\title{
Nurses Challenges of Supporting Hospitalized Patients Regarding Sexual-Health Issues
}

\author{
Anette C Ekstrom ${ }^{1 *}$, Lena Nilsson ${ }^{1}$, Caroline Apell ${ }^{2}$, David Palmius ${ }^{3}$, Lena B Martensson ${ }^{1}$ \\ ${ }^{1}$ School of Health and Education, University of Skovde, P.O. Box 408, SE-54128 Skovde, Sweden \\ ${ }^{2}$ The Municipality of Alingsas, SE-44181 Alingsas, Sweden \\ ${ }^{3}$ Skaraborg Hospital Skovde, SE-54182 Skovde, Sweden
}

"Corresponding author: Anette C Ekstrom, School of Health and Education, University of Skövde, P.O. Box 408, SE-54128 Skövde, Sweden, Tel: 0500-448414; E-mail: anette.ekstrom@his.se

Received date: Jan 04, 2016, Accepted date: Apr 26, 2016, Published date: May 04, 2016

Copyright: ( $) 2016$ Ekstrom AC, et al. This is an open-access article distributed under the terms of the Creative Commons Attribution License, which permits unrestricted use, distribution, and reproduction in any medium, provided the original author and source are credited.

\begin{abstract}
Background: The approach to nursing should be characterized by a holistic view of the human being which includes sexual health. From a nursing perspective, it is therefore of most importance to have a dialogue about factors associated with sexual health also among hospitalized patients. However, to our knowledge there is a lack of qualitative studies regarding nurses attitudes about dialogue with patients about sexual health.
\end{abstract}

Objective: To investigate nurses attitudes towards dialogue with hospitalized patients about sexual health.

Methods: A qualitative method was used and interviews were conducted which then were analyzed using a qualitative content analysis. Eleven registered nurses were included, the inclusion criteria was: at least one year of experience as a nurse and working on a medical or surgical ward in a hospital in the southwest of Sweden. The participants were in the ages 25-65 and had worked as nurses between 2 and 30 years. Nine of the participants were women. The data were collected during 2011.

Results: The nurses experiences of and reflections on dialogue with patients about sexual health were presented as a single main theme: Nurses challenges to support hospitalized patients with sexual health issues. This theme had three categories: Feeling uncomfortable, Feeling inadequate and Task-oriented care with related subcategories respectively.

Conclusions: Nurses attitudes towards their dialogues about sexual health with hospitalized patients were less challenging if they were initiated by the patients or if the patients were men with medical causes related to sexual health. Lack of knowledge and support from colleagues became reasons why nurses felt inadequate about discussing sexual health with their patients.

Keywords: Sexual health; Nursing care; Qualitative analysis; Dialogue

\section{Introduction}

Sexual health is present throughout life, regardless of the individuals age, [1,2]. According to the definition by the World Health Organization, sexual health is "... a central aspect of being human throughout life... and sexual health is ... a state of physical, emotional, mental and social well-being in relation to sexual health" [3] and "...is influenced by the interaction of biological, psychological, social, economic, political, cultural, legal, historical, religious and spiritual factors." [3]. From a nursing perspective, it is therefore of great importance to be aware of factors associated with sexual health also among older people [4]. Higgins et al., [5] describe sexual health as an important aspect of good quality of life and even more important when sexual health is threatened by disease. There are a lot of aspects which have an impact on sexual health. For instance, in relation to type 2 diabetes [6], stroke [7], and prostatectomy [8] sexual health may be affected. Further psychotropic medication could have an impact on sexual health [9], for example after hysterectomy [10]. However, sexual health does not only include somatic function or dysfunction but also the psychological and existential aspect of a human being [3]. Briggs [11] states that sexual health is not only limited by the physical impact of disease but also by anxiety and self-experienced ill-health.

On the one hand, it is the nurses responsibility to talk about sexual health in an informative and responsive manner [5], on the other hand, it has been reported that nurses avoid illuminating sexual health with patients even if they are aware of their responsibility regarding this issue [12,13]. Education is an important aspect to overcome nurses perceived barriers of social and personal perceptions in relation to supporting patients sexual health [14]. It has been stated that nurses also lack the confidence to bring up the subject with the patient $[15,16]$; they do not feel comfortable enough [13] and they are reluctant to initiate a conversation related to sexual health and therefore await the patients initiative [5,17]. Further, there are also other barriers such as appropriate customized environments in the ward $[18,19]$ and insufficient time to discuss these matters with the patient [13] and therefore it is challenging for nurses to create a private dialogue about sexual health with the patients. Nurses experience conflicting feelings when talking to patients about sexual health; 
however, the ones who actually talk about sexual health have a strong desire to help their patients [20]. Important when offering support are non-judgmental attitudes [21] as well as an understanding of unique support needs and knowledge of the specific supportive situation [21-25]. The professional provider may also hesitate to offer support from fear of inflicting harm [26]. Attitudes are based on feelings for and a varying degree of knowledge about a specific phenomenon [27] and could be described as the individuals disposition to act or respond in a positive or a negative way in relation to this phenomenon [28]. Although sexual-health care is often not prioritized in practice, nurses are in a prime position to promote sexual health and well-being for patients. In summary, to our knowledge there is a lack of qualitative studies regarding nurses attitudes and dialogue with patients about sexual health. It is therefore important to increase knowledge about the nurses views about their insufficient dialogue and documentation regarding patient's sexual health. Therefore, this study aims to investigate nurses attitudes towards dialogue with hospitalized patients about sexual health.

\section{Methods}

\section{Design}

A qualitative design with content analysis [29] was chosen for this study. It was decided that the most suitable data collection method was individual interviews since the direct voices of the nurses can provide information about meaningful values and life experiences [30]. This data collection method aimed to elucidate the participants perception [31] of dialogue about sexual health with hospitalized patients.

\section{Participants}

To ensure variation, a purposive sampling strategy was adopted $[32,33]$ regarding age, gender, and years of experience as a nurse. Eleven registered nurses who fulfilled criteria of at least one year of experience as a nurse and working on a medical or surgical ward or in a hospital in the southwest of Sweden participated in the study. They were between 25 and 65 years of age and they had worked as nurses between 2 and 30 years. Nine of the participants were women and two were men. In their daily work, the participants met patients with different medical and surgical illnesses which could have an impact on sexual health.

\section{Data collection procedure}

Access to the informants was gained through the head of the medical or surgical ward. Information about the study was given during workplace meetings. Thereafter, the head of each ward asked the nurses if they were willing to participate. None of the nurses had any previous relationship with the researchers responsible for the study. The nurses who met the inclusion criteria and who fulfilled the purposive sampling criteria were approached by this head of the ward. The nurses were informed about the study and asked to give their consent to participate in the study. Thereafter, the interviews were conducted by two of the authors, CA and DP, who alternated during the interview with the exception of one interview which was conducted by CA alone. The interviews were held at the ward in a secluded room or in an office were the interview could be in private [34]. The average length of the interviews was 30 minutes, starting with an interview guide containing themes about age, gender, and years of experience as a nurse. The interviews were digitally recorded and all the recorded interviews were transcribed verbatim before an analysis was made. The data were collected during 2011.

The nurses were asked to talk about their experiences of dialogue with patients about sexual health. The interview started with an open question "Can you tell us about your experiences talking with patients about sexual health?" This open question was followed by questions aiming to encourage the nurses to freely elaborate on the description of their experiences. Probing questions such as "Could you explain more?" were used to create a deeper understanding of the nurses answers.

The audio-taped interviews with the nurses were transcribed verbatim and analysed separately using latent content analysis [29]. Data collection and analysis were carried out simultaneously, in part to follow up the issues that were emerging but also to decide when saturation of the topics and the respondents had been reached [35].

\section{Data analysis}

Content analysis is a stepwise process of categorization based on the expression of thoughts, feelings, and actions described throughout the text [29]. The intentions of the analytical process are to remain close to the words of the text and to bring out the contextual meanings. The material was analyzed according to a model described by Graneheim and Lundman [29]. In the first phase, the material was read several times to create comprehension of the material. The authors initially read the material separately and then together. When the authors were familiar with the material, the analysis moved on to the second phase. In that phase, units which emphasized a meaning were detected with focus on differences and similarities. The questions the authors had in mind during this process were in line with what was said in the text, how it was said and the meaning of what was said. The authors highlighted meaning units and placed similar parts into subcategories. In the third phase, the units were put together and the material became presentable with focus now on the new comprehension that emerged from the material [29]. Subcategories were formed according to similarities and differences in the nurses perceptions. All subcategories of a similar kind were put together and formed new main categories. In order to achieve trustworthiness in the data analysis, the concepts credibility, dependability, and transferability were taken into account. We made certain that the analysis agreed with the purpose; the entire material was analyzed simultaneously and all authors read through the text material to ensure that the material was categorized appropriately. Moreover, the context and the participants were described as clearly as possible to facilitate the transferability of the results [36]. In the final step, data were analyzed by reading across the categories, searching for new associations and meanings and in this process the theme was identified.

\section{Ethical considerations}

Permission to carry out this study was given by the head nurse at each ward. The procedure followed the principles of the Declaration of Helsinki [37]. The participants received written and oral information including participation being voluntary and that they could withdraw their participation at any time without explanation. According to Swedish law [38], no ethical approval is required when the study does not include patients. 


\section{Results}

The nurses experiences of and reflections on dialogue with patients about sexual health were presented as a single main theme: Nurses challenges to support hospitalized patients with sexual-health issues. This theme had three categories: Feeling uncomfortable, Feeling inadequate and Task-oriented care with related subcategories respectively (Table 1). Each category and their subcategories were presented using direct quotations in a conversational format. A code number for each respondent is included after the quotation here below (Nurse: N1-N11).

\begin{tabular}{|l|l|l|}
\hline Subcategories & Categories & Theme \\
\hline Taboo & Feeling uncomfortable & \\
\hline Prejudices include gender & & $\begin{array}{l}\text { Nurses challenges of supporting hospitalized patients with sexual-health } \\
\text { issues }\end{array}$ \\
\hline Patients' initiative and responsibility & & \\
\hline Lack of knowledge & Feeling inadequate & \\
\hline Education & & \\
\hline The working groups influence & & \\
\hline Medical problems was easier to relate to sexual health & Task-oriented care & \\
\hline & & \\
\hline $\begin{array}{l}\text { Sexual health has low priority during the acute phase of a } \\
\text { disease }\end{array}$ & & \\
\hline
\end{tabular}

Table 1: Categories with subcategories and theme identified from interviews with nurses.

\section{Feeling uncomfortable}

The nurses described feeling uncomfortable when discussing sexual health with patients. They highlighted that discussions about sexual health sometimes felt taboo and therefore was often avoided because of their own prejudices. However, the nurses thought that it was easier to discuss sexual health when the patients initiated the dialogue although they did not feel comfortable enough to initiate a dialogue themselves. They also thought that the patients were not comfortable discussing sexual health with the nurses.

\section{Taboo}

A perceived overall taboo was sometimes the main reason for the nurses not to initiate dialogue about sexual health with the patients. They emphasized that sexual health was not discussed neither with patients nor colleagues and was therefore a subject which was not focused on. The taboo did not only include the staff and the nurses in the study, but it was also presumed that patients considered sexual health to be something that was private and taboo.

\section{... I do not talk about sexuality, with anyone... (N11)}

Prejudices included gender

One barrier for the nurses to initiate a dialogue about sexual health was their own prejudices which made them uncomfortable. The prejudices included gender age and the relationship status of the patient. The nurses mentioned that the dialogue about sexual health was often focused on men who had medical treatment or had had surgery which could have an impact on their sexual health. They believed that women's sexual health was not affected in the same way and that women were not considered as sexual beings to the same extent as men. The informants were also affected by the patients relationship status because of the nurses prejudice that patients who were not in a relationship did not have a sexual life.

One expects maybe that if you live in a relationship and you also have an intimacy together. Ehm ... I do not think about that you have a life together in the same way when you are single, but of course one has a sexual life anyway. (N5)

The informants stressed that it was important to be aware of their own attitudes to be able to have a dialogue about sexual health for patients.

Sexuality keeps you on course for many years, many younger people believe that people stop just because you are 40 or older. But here they are older than that, so that's a topic we need to address, it is important! (N7)

\section{Patients initiative and responsibility}

The nurses mentioned that a dialogue about sexual health was held on the patients terms. A majority of the informants expressed the opinion that it was easier to discuss sexual health if it was on the patients initiative. They felt that the patient should initiate the dialogue if they had problems, which meant that the nurses disclaimed any responsibility for the patients sexual health. However, some of the nurses highlight that it was important to raise the issue to show the patients that it was essential to discuss the subject, if the patients wanted this.

But it's more that you raise the question, many times I can feel that it's enough to just open up, so they feel it's okay to talk about it. (N6). 


\section{Feeling inadequate}

The nurses stated that they had a feeling of being inadequate when it came to starting a dialogue about sexual health with patients. They were afraid of talking about issues they could not help the patient with and they described their knowledge as limited. Further, all of the respondents expressed how sexual-health was absent in their training to become a nurse. Some of them had participated in theme days about sexual health, but they experienced this as insufficient. Knowledge and experiences about sexual health were not shared between colleagues which increased their feeling inadequate.

\section{Lack of knowledge and education}

The informants felt that they lacked education and knowledge about sexual health in their training to become a nurse which made initiating a dialogue about sexual health more difficult. The nurses were worried that they could not provide sufficient support regarding sexual health. Therefore they too often avoided the topic.

For the patient it is about to continue living. So really, you should bring this up more. But I do not really feel that I have the tools to do it in a good way. (N4)

Education was as an important factor for the nurses. It gave them better knowledge and tools to provide support and to have a dialogue with the patients. The informants highlighted that their own private experiences influenced their dialogue with the patients, which made it difficult to offer good support.

I think we need education and perhaps guidance in discussing this type of topics, in a comfortable and secure way for both ourselves and the patient. (N5).

\section{The working group's influence}

The colleagues support was of great importance for the nurses in their work. Sharing knowledge and discussing the approach to various issues were of great importance. However, they perceived it as unfortunate that the patients sexual health was an issue being discussed only to a very limited extent. Furthermore, it was stressed that it was important to talk about sexual health within the working group.

... It would be good to discuss this in the staff group between us nurses. Why is it difficult to talk and advise each other about this, we are doing it in many other subjects? (N5)

The nurses pointed out that they had had theme days when the topic was discussed, although without continuing the discussion afterwards. This reinforced their feeling that the topic was not relevant to discuss with the patients and colleagues.

\section{Task-oriented care}

The results show that it was obvious that the care of the patient is task-oriented. The nursing care is much too often focused on practical issues and the nurses state it is easily the case that priority is not given to dialogue about sexual health if the issue is not of a medical character.

\section{Medical problems were easier to relate to than sexual health}

The nurses stated that it was not easy to give priority to a dialogue with the patients about sexual health if the issue was not of medical causes. Medical causes, for example, could be erectile dysfunction caused by blood-pressure treatment where it was possible to prescribe drugs for erectile dysfunction.

If the patient gets any side effect associated with the diseases or the medication you may bring it up trying to get help, otherwise I don't think it is common to bring it up... [11]

Sexual health has low priority during the acute phase of a disease

It became clear that sexual health had low priority, especially during the acute phase of a disease. The nurses described how the focus for the patient was to regain health and therefore sexual health had no place during hospitalization. However, they pointed out that the patients maybe had questions about sexual health when they were discharged from the hospital.

Thus, it has not the highest priority soon after an acute event.../...It is probably something that could be an issue later... [13]

\section{Nurses challenges of supporting hospitalized patients with sexual-health issues}

The main theme showed that nurses had challenges of supporting hospitalized patients with sexual-health issues, something which often was a result of the nurses own uncertainty and priority given to medical causes. They highlighted that sexual health much too often was taboo and therefore they avoided this issue in their professional support. The dialogue about sexual health was usually focused on men while women were not considered as sexual beings to the same extent. The informants said that it was easier to discuss sexual health if it was on the patients initiative. Lack of knowledge and lack of support from colleagues was a major reason why nurses felt inadequate to discuss sexual health with patients. Education was an important factor that would give the nurses tools and knowledge in order to perform dialogues about sexual health.

\section{Discussion}

As mentioned above, the results showed that nurses felt challenges when supporting hospitalized patients with sexual-health issues which often was affected by uncertainty and a priority to medical causes. The respondents felt uncomfortable initiating a dialogue about sexual health with patients. On the other hand, if it was the patient's initiative, they did not have this feeling. This attitude puts the responsibility on the patient and the nurses meant that it was the patient's responsibility to initiate the dialogue if a problem existed. This is something also described by Higgins, Barker and Begley [5], and Guthrie [17] who mention that nurses largely await the patient's initiative. A clearly distinguishable category of feeling uncomfortable was based on sexual health as private and experienced by the nurses as a taboo subject. It became clear that sexual health was not something that was openly discussed among colleagues and thus also hampered the dialogue with the patient. Research shows that the professional support provider may also hesitate to offer support from fear of inflicting harm [26] and it is important when offering support to express non-judgmental attitudes [21] as well as an understanding of unique support needs and knowledge of the specific supportive situation [22-24].

Age was another factor of the prevailing prejudices about sexual health as described by the nurses. Although the nurses stressed that age should not be a deciding factor in the initiation of dialogue about sexual health, they anyway described how their prejudices about an elderly patient's sexual health prevented them from bringing this up. 
Peate [1] emphasizes that sexual health has no age limit, something which is supported by Skoog [39] who highlights that old people continue to be sexually active, a view that is in line with the definition by the World Health Organization [3]. Another noticeable prejudice was that individuals not in relationships were not sexually active, which was based on the idea that only those who live in a relationship were expected to have a sexual relation. This prejudice could be reasons the nurses did not initiate a dialogue with a patient who were not in a relationship.

The result showed that the nurses had a feeling of being inadequate when it came to starting a dialogue with patients about sexual health due to limited knowledge. Further, all of the respondents meant that sexual health was absent in their training to become a nurse and theme days. In addition, knowledge and experiences about sexual health were not shared between colleagues who increased their feelings of being inadequate. This pattern of feeling inadequate is confirmed by Price [15] who highlights that most of the nurses do not feel confident enough to start a dialogue about sexual health. According to Higgins et al [5], the nurses themselves need to admit sexual health as something important for human beings as well as becoming aware that patients have a desire for nurses to bring this topic up.

Another significant result is that the nurses described their work as task-oriented which meant that if they wanted to initiate a dialogue about sexual health, it required that the problem had medical causes. This was exemplified by the prescription of drugs for problems of erectile dysfunction. Further, dialogue about sexual health often focused on eliminating physical barriers to be able to be sexually active. Briggs [11] and Peate [1] describe how the nurses role is to advise the patient about possible side effects of the drugs and that they should be able to give the patient advice and support when side effects occur. The informants also highlighted the problem that they felt it was of major importance to give priority to more urgent problems of the patient and that it was likely that the patient did not always feel that it was relevant to discuss sexual health. There is an underlying mix of sexual function and sexual health, which are not the same concepts although they are inter-related, something that needs to be discussed. Professionals dialogue with patients about sexual health therefore had low priority.

In addition, safe care requires proper documentation; however, documentation is inadequate, much too often due to lack of time and knowledge $[40,41]$. A patient's medical record has many different functions and should reflect the contents of the main components of care [42]. VIPS is a model for nursing documentation and consists of keywords in a person's nursing history, status, and measures of nursing work [42]. Sexual health is one of the keywords, but too often documentation under the keyword sexual health is missing.

However, a minority of the informants stated that even during hospitalization, it might be necessary to open up discussions about sexual health for the patient to feel comfortable to return to this issue at a later stage. Health is a combination of physical and mental wellbeing in a holistic perspective [3]. The dialogue should therefore not only focus on knowledge provision but also aim to provide support and confirmation. This is a challenge for the nurses who need good training and support in order to promote sexual health throughout life.

\section{Limitations}

Throughout the study, various steps were considered and taken in order to enhance the trustworthiness of the study. In qualitative research; credibility, dependability, confirmability, and transferability build trustworthiness [43]. Individual interviews were chosen as the data-collection method; interviews made it possible to grasp the individuals narratives which could provide information about meaningful values, experiences, and reflections [30]. To ensure variation, a purposive sampling strategy was adopted [32,33] regarding age, gender, and years of experience as a nurse. The interviews were performed by two of the authors. One of the authors conducted the interview and the other observed. This was a positive strategy for the interview technique, which provides dependability. The study is limited by its small sample size, but the context and the participants are described as clearly as possible to facilitate the transferability of the results [30]. Data collection and analysis were carried out simultaneously, in part to follow up the issues that were emerging but also to decide when saturation of the topics and the respondents had been reached [35]. Thus, it is our estimation that the content of the interviews was adequate, especially since in the interviews analysed at the latest stage, no new conclusions emerged. In order to strengthen the credibility of the present study, the analysis process was performed individually as well as jointly discussed between the authors. The confirmability quotations are presented in the results, which enables validation of the relevance of the nurses attitudes. Nurses who met the inclusion criteria were strategically included to enable as many variations of perceptions as possible. We have described the setting and data collection procedure as clearly as possible in order to promote the transferability of design and findings.

\section{Conclusions}

Nurses attitudes towards their dialogues about sexual health with hospitalized patients were less challenging if they were initiated by the patients or if the patients were men with medical causes related to sexual health. Lack of knowledge and support from colleagues became reasons why nurses felt inadequate about discussing sexual health with their patients.

\section{Relevance to Clinical Practice}

To offer adequate professional support for patients sexual health, education is an important factor. Education gives the nurses tools to reflect on their own attitudes and hence to facilitate their dialogue about sexual health with the hospitalized patients, especially with women.

\section{Acknowledgements}

We want to express our appreciation to all the nurses who participated in this study.

\section{What does this paper contribute to the wider global clinical} community?

On the topic of dialogue about sexual health with hospitalized patients, this study contributes the following:

- Knowledge about nurses having feelings of being uncomfortable and that their challenges of talking about sexual health are affected by their own uncertainty and a priority given to medical issues.

- Education is an important factor that gives the nurses tools to reflect on their own attitudes and hence to facilitate their dialogues about sexual health with the hospitalized patients, especially women. 


\section{Funding}

The study was funded by the University of Skovde, Sweden.

\section{References}

1. Peate I (2004) Sexuality and sexual health promotion for the older person. Br J Nurs 13: 188-193.

2. Mercer CH, Tanton C, Prah P, Erens B, Sonnenberg P, et al. (2013) Changes in sexual attitudes and lifestyles in Britain through the life course and over time: findings from the National Surveys of Sexual Attitudes and Lifestyles (Natsal). Lancet 382: 1781-94.

3. World Health Organization. Sexual and reproductive health 2006.

4. Killinger KA, Boura JA, Diokno AC (2014) Exploring factors associated with sexual activity in community-dwelling older adults. Res Gerontol Nurs 7: 256-263.

5. Higgins A, Barker P, Begley CM (2006) Sexuality: the challenge to espoused holistic care. Int J Nurs Pract 12: 345-351.

6. Tamas V, Kempler P (2014) Sexual dysfunction in diabetes. Handb Clin Neurol 126: 223-232.

7. Korpelainen JT, Kauhanen ML, Kemola H, Malinen U, Myllylä VV (1998) Sexual dysfunction in stroke patients. Acta Neurol Scand 98: 400-405.

8. Benson CR, Serefoglu EC, Hellstrom WJ (2012) Sexual dysfunction following radical prostatectomy. J Androl 33: 1143-1154.

9. Higgins A (2007) Impact of psychotropic medication on sexuality: literature review. Br J Nurs 16: 545-550.

10. Vomvolaki E, Kalmantis K, Kioses E, Antsaklis A (2006) The effect of hysterectomy on sexuality and psychological changes. The European journal of contraception \& reproductive health care: the official journal of the European Society of Contraception 11:23-7.

11. Briggs LM (1994) Sexual healing: caring for patients recovering from myocardial infarction. Br J Nurs 3: 837-842.

12. Jaarsma T, Stromberg A, Fridlund B, De Geest S, Martensson J, et al (2010) Sexual counselling of cardiac patients: nurses' perception of practice, responsibility and confidence. European journal of cardiovascular nursing : journal of the Working Group on Cardiovascular Nursing of the European Society of Cardiology 9: 24-9.

13. Saunamaki N, Andersson M, Engström M (2010) Discussing sexuality with patients: nurses' attitudes and beliefs. J Adv Nurs 66: 1308-1316.

14. East L, Hutchinson M (2013) Moving beyond the therapeutic relationship: a selective review of intimacy in the sexual health encounter in nursing practice. J Clin Nurs 22: 3568-3576.

15. Price B (2010) Sexuality: raising the issue with patients. Cancer Nursing practice 9: 29-35.

16. Shuman NA, Bohachick P (1987) Nurses' attitudes towards sexual counseling. Dimens Crit Care Nurs 6: 75-81.

17. Guthrie C (1999) Nurses' perceptions of sexuality relating to patient care J Clin Nurs 8: 313-321.

18. Kim S, Kang HS, Kim JH (2011) A sexual health care attitude scale for nurses: development and psychometric evaluation. Int J Nurs Stud 48: 1522-1532.

19. Nakopoulou E, Papaharitou S, Hatzichristou D (2009) Patients' sexual health: a qualitative research approach on Greek nurses' perceptions. J Sex Med 6: 2124-2132.

20. Saunamaki N, Engström M (2014) Registered nurses' reflections on discussing sexuality with patients: responsibilities, doubts and fears. J Clin Nurs 23: 531-540.
21. Oakely A. Giving support in pregnancy; the role of research midwives in a randomized controlled trial. Midwives, Research and Childbirth. 3 London: Chapman \& Hall.; 1994. p. 30-63.

22. Langford CP, Bowsher J, Maloney JP, Lillis PP (1997) Social support: a conceptual analysis. J Adv Nurs 25: 95-100.

23. Oakley A (1994) Giving support in pregnancy; the role of research midwives in a randomized controlled trial, Midwives, Research and Childbirth. 3. London: Chapman \& Hall 30-63.

24. Hupcey JE (1998) Clarifying the social support theory-research linkage. J Adv Nurs 27: 1231-1241.

25. Langford CP, Bowsher J, Maloney JP, Lillis PP (1997) Social support: a conceptual analysis. J Adv Nurs 25: 95-100.

26. Schumaker S, Brownell A (1984) Towards a theory of social support: closing conceptual gaps. Journal of social issues 4: 11-36.

27. Zanna M, Rempel J (1986) Attitudes, a new look at an old concept. The social psychology of knowledge, University Press, Camebridge.

28. Ajzen I (2005) Attitudes, personality and behavior. 2nd ed. Maidenhead, Berkshire: Open University Press.

29. Graneheim UH, Lundman B (2004) Qualitative content analysis in nursing research: concepts, procedures and measures to achieve trustworthiness. Nurse Educ Today 24: 105-112.

30. Kvale S (1996) Interviews: an Introduction to Qualitative Research Interviewing. California.: Sage Publications.

31. Drennan J (2003) Cognitive interviewing: verbal data in the design and pretesting of questionnaires. J Adv Nurs 42: 57-63.

32. Patton M (2002) Qualitative research and evaluation methods. 3 ed. California: Sage; 2002.

33. Polit D, Beck C (2004) Nursing research principles and methods. 7 ed. Philadelphia: Lippincott Williams \& Wilkins.

34. Kvale S (1997) Den kvalitativaforskningsintervjun [The qualitative research interview]: Studentlitteratur.

35. Mayan M (2001) An introduction to qualitative methods: A training module for students and professionals.: University of Alberta: International Institute for Methodology.

36. Morse J, Barrett M, Mayan M, Olson K, Spiers J (2002) Verification Strategies for Establishing Reliability and Validity in Qualitative Research. International Journal of Qualitative Methods.

37. Declaration of Helsinki (2002) World Medical Association Declaration ethical principles for medical research involving human subjects. J Postgrad Med 48: 206-8.

38. Law for ethical review of research involving humans 2003: 460.

39. Skoog I (1996) Sex and Swedish 85-year olds. N Engl J Med 334: 1140-1141.

40. Ehrenberg A (2001) Nurses perceptions concerning patient records in Swedish nursing homes. Nordic Journal of Nursing Research 21: 9-14.

41. Nordström G, Gardulf A (1996) Nursing documentation in patient records. Scand J Caring Sci 10: 27-33.

42. Ehnfors M, Thorell-Ekstrand I, Ehrenberg A (1991) Towards basic nursing information in patient records. Vard Nord Utveckl Forsk 11: 12-31.

43. Lincon Y, Guba E (1985) Naturalistic Inguiry. London: Sage Publications Inc. 